\title{
Normally-off AlGaN/GaN MIS-HEMT with low gate leakage current using a hydrofluoric acid pre-treatment
}

\author{
Gokhan Kurt $^{\mathrm{a}, \mathrm{b}, *}$, Melisa Ekin Gulseren ${ }^{\mathrm{b}, \mathrm{c}}$, Turkan Gamze Ulusoy Ghobadi ${ }^{\mathrm{d}, \mathrm{e}}$, Sertac Ural ${ }^{\mathrm{b}}$, \\ Omer Ahmet Kayal ${ }^{\mathrm{b}}$, Mustafa Ozturk ${ }^{\mathrm{b}}$, Bayram Butun ${ }^{\mathrm{b}}$, Mehmet Kabak ${ }^{\mathrm{a}}$, Ekmel Ozbay ${ }^{\mathrm{b}, \mathrm{c}, \mathrm{d}, \mathrm{f}}$ \\ ${ }^{a}$ Department of Engineering Physics, Faculty of Engineering, Ankara University, 06100 Ankara, Turkey \\ ${ }^{\mathrm{b}}$ Nanotechnology Research Center, Bilkent University, 06800 Ankara, Turkey \\ ${ }^{\mathrm{c}}$ Department of Electrical and Electronics Engineering, Bilkent University, 06800 Ankara, Turkey \\ ${ }^{\mathrm{d}}$ UNAM-Institute of Materials Science and Nanotechnology, Bilkent University, 06800 Ankara, Turkey \\ ${ }^{\mathrm{e}}$ Department of Energy Engineering, Faculty of Engineering, Ankara University, 06830 Ankara, Turkey \\ ${ }^{\mathrm{f}}$ Department of Physics, Bilkent University, 06800 Ankara, Turkey
}

\section{A R T I C L E I N F O}

The review of this paper was arranged by Prof. E. Calleja

Keywords:

$\mathrm{GaN}$

Gate leakage current

HEMT

Hysteresis

Normally-off

Pre-treatment

\begin{abstract}
A B S T R A C T
We demonstrate the electrical performances of an AlGaN/GaN metal-insulator-semiconductor high electron mobility transistor (MIS-HEMT) with low gate leakage current $\left(\mathrm{I}_{\mathrm{g}}\right)$. A low gate leakage current as low as the order of $10^{-11} \mathrm{~A} / \mathrm{mm}$ was achieved from normally-off MIS-HEMT device $\left(\mathrm{V}_{\text {th }}=2.16 \mathrm{~V}\right)$ with a partially recessed gate, fluorine treatment, and $\mathrm{ALD} \mathrm{Al}_{2} \mathrm{O}_{3}$ gate dielectric layer. The gate leakage current decrease is attributed to the pre-treatment of the gate region with hydrofluoric acid (HF) and deionized water (DI) solution, which acts to remove the native oxide layer and thus decrease interface traps. X-ray photoelectron spectroscopy (XPS) and atomic force microscopy (AFM) analyses demonstrate that the AlGaN surfaces are modified such that the surface roughness and native oxide introduced by the treatments used to achieve normally-off operation are remedied with the use of the pre-treatment.
\end{abstract}

\section{Introduction}

GaN based high-electron mobility transistors (HEMTs), owing to the intrinsic advantages of GaN such as wide bandgap, high electron mobility, and high breakdown voltage, have proven their superiority for high power and high frequency applications. The primary drawbacks of GaN based transistors are normally-on operation and high gate-source leakage current resulting from the conventional Schottky gate structure. Approaches such as gate recess [1], p-GaN gate [2], and fluorine treatment [3] have been demonstrated to achieve normally-off operation. Gate recess on its own results in higher ON-state gate leakage current and decreased gate voltage swing; thus, normally-off devices are commonly fabricated combining gate recess and metal-insulatorsemiconductor (MIS) approaches [4,5]. A fully recessed barrier, however, results in degraded channel mobility and increased channel resistance, which leads to low current densities and large on-resistance $[6,7]$. These issues are overcome with a partial recess, in which a thin barrier layer remains, at the cost of a less positive threshold voltage.
Fluorine treatment of the gate region using plasma based systems is used to implant fluorine ions in the barrier layer and recover the threshold voltage, however, it has been demonstrated that fluorine implantation results in trap generation in the barrier layer [8], which indicates that there is possibility for improvement of the gate leakage characteristics in such devices.

Many methods for the reduction of gate leakage current have been reported in the literature such as post-gate annealing [9], pre-gate surface treatments [10], plasma treatments [11], p-InGaN cap [12], and oxide-filled isolation technique [13]. For normally-on devices, minimum reported gate leakage currents are in the order of $10^{-10}-10^{-11} \mathrm{~A} / \mathrm{mm}[13,14]$. Ref. [15] reports gate leakage currents on the order of $10^{-8} \mathrm{~A} / \mathrm{mm}$ for recessed-gate normally-off MOS-HEMT devices, and [16] reports forward gate leakage currents on the order of $10^{-11} \mathrm{~A} / \mathrm{mm}$ for a normally-off GaN MIS-HEMT with fluorine doped gate insulator.

In a previous study [17], we have demonstrated that for a hybrid approach of obtaining normally-off operation using recess etching and

\footnotetext{
* Corresponding author at: Department of Engineering Physics, Faculty of Engineering, Ankara University, 06100 Ankara, Turkey.

E-mail addresses: gokurt@bilkent.edu.tr (G. Kurt), cmelisa.gulseren@bilkent.edu.tr (M.E. Gulseren), egamze.ulusoy@bilkent.edu.tr (T.G.U. Ghobadi), sertac.ural@bilkent.edu.tr (S. Ural), omer.kayal@bilkent.edu.tr (O.A. Kayal), mozturk@bilkent.edu.tr (M. Ozturk), bbtn@bilkent.edu.tr (B. Butun), Mehmet.Kabak@ankara.edu.tr (M. Kabak), ozbay@bilkent.edu.tr (E. Ozbay).
} 
fluorine treatment, gate leakage characteristics display minimal variation with process modifications. Thus, an alternative approach is required in order to obtain improvement in the gate leakage. In this study, we report a fabrication process of a normally-off GaN MIS-HEMT with a gate leakage current as low as on the order of $10^{-11} \mathrm{~A} / \mathrm{mm}$ by exploiting a hydrofluoric (HF) acid pre-treatment prior to gate formation.

\section{Device structure and fabrication}

The fabricated HEMT structures consist of a $300 \mathrm{~nm}$ AlN nucleation and AlGaN strain managing layer stack on a Si substrate, followed by $1150 \mathrm{~nm}$ of a low $\mathrm{Al}$ content $\mathrm{Al}_{\mathrm{x}} \mathrm{Ga}_{1-\mathrm{x}} \mathrm{N}$ (x: 0.05) buffer, $110 \mathrm{~nm}$ of a high mobility channel GaN, $1 \mathrm{~nm}$ AlN spacer, $27 \mathrm{~nm} \mathrm{Al}_{0.26} \mathrm{Ga}_{0.84} \mathrm{~N}$ barrier, and a $3 \mathrm{~nm}$ unintentionally doped GaN cap layer. The mobility and 2DEG density were found to be $6.7 \times 10^{12} \mathrm{~cm}^{-2}$ and $1425 \mathrm{~cm}^{2} \mathrm{~V}^{-1} \mathrm{~s}^{-1}$, respectively, by contactless Hall measurements. The fabrication started with mesa isolation by inductively coupled plasma reactive ion etching (ICP-RIE) using $\mathrm{BCl}_{3}$ and $\mathrm{Cl}_{2}$ gases. E-beam evaporation method was used to deposit $\mathrm{Ti} / \mathrm{Al} / \mathrm{Ni} / \mathrm{Au}$ metals for Ohmic contacts, followed by rapid thermal annealing (RTA) with a 3-step annealing process in $\mathrm{N}_{2}$ ambient. The RTA process consisted of steps at $400{ }^{\circ} \mathrm{C}$ for $180 \mathrm{~s}, 700^{\circ} \mathrm{C}$ for $40 \mathrm{~s}$, and $830^{\circ} \mathrm{C}$ for $30 \mathrm{~s}$, respectively. The Ohmic contact resistance was extracted as $0.40 \mathrm{Ohm} . \mathrm{mm}$ using the transfer length method (TLM). Gate fingers were defined with optical lithography, and partially recess etched using ICP-RIE with a low power (RF: $5 \mathrm{~W}$, ICP: $300 \mathrm{~W}$ ) $\mathrm{BCl}_{3} / \mathrm{Cl}_{2}$ recipe to achieve an etch depth of $10 \mathrm{~nm}$. Subsequently, $\mathrm{F}^{-}$treatment was carried out for $10 \mathrm{~min}$ using $\mathrm{SF}_{6}$ gas with ICP-RIE. Prior to atomic layer deposition (ALD) in the gate regions, acid pre-treatment consisting of hydrofluoric acid (HF) and deionized water (DI) $(1: 14)$ rinse for $8 \mathrm{~s}$ was applied. It has been reported that an appropriate acid pre-treatment prior to $\mathrm{ALD} \mathrm{Al}_{2} \mathrm{O}_{3}$ deposition has a mitigating effect on interface trap densities [18,19]. After the cleaning procedure, a 10 -nm-thick $\mathrm{Al}_{2} \mathrm{O}_{3}$ layer was deposited at $200^{\circ} \mathrm{C}$ by ALD, employing Trimethylaluminium as the $\mathrm{Al}$ precursor, and $\mathrm{DI}$ water as the $\mathrm{O}$ precursor. Pulse times of the $\mathrm{Al}$ precursor and $\mathrm{O}$ source were both $0.015 \mathrm{~s}$, and the purge times were chosen as $10 \mathrm{~s}$. The process was conducted in an $\mathrm{N}_{2}$ ambient with gas flow of $20 \mathrm{sccm}$. The gate regions were redefined with optical lithography. Ni/Au (50/ $300 \mathrm{~nm}$ ) e-beam evaporation and lift off were carried out to form the gate electrodes. For device passivation, $240 \mathrm{~nm} \operatorname{SiN}_{\mathrm{x}}$ dielectric layer was deposited with plasma enhanced chemical vapor deposition (PECVD). The fabrication was completed with the formation of connection pads. A standard normally-off MIS-HEMT with a similar process flow except for the omission of HF pre-treatment was fabricated as a reference. The dimensions of the devices were $\mathrm{L}_{\mathrm{DS}}=9 \mu \mathrm{m}, \mathrm{L}_{\mathrm{GS}}=2 \mu \mathrm{m}$, and $\mathrm{L}_{\mathrm{G}}=2 \mu \mathrm{m}$. The fabricated devices have gate finger dimensions of $10 \times 1000 \mu \mathrm{m}$. Fig. 1 shows the schematic cross-section with dimensions and a micrograph of the AlGaN/GaN normally-off MIS-HEMT.

\section{Measurement results and discussion}

$\mathrm{C}-\mathrm{V}$ measurements were performed on treated $\mathrm{Al}_{2} \mathrm{O}_{3} / \mathrm{GaN}$ MIS diodes without and with HF pre-treatment at a frequency of $100 \mathrm{kHz}$ in order to investigate the impact of the HF pre-treatment on the interface quality. The capacitors went through the same device process steps. For the $\mathrm{Al}_{2} \mathrm{O}_{3} / \mathrm{GaN}$ MIS-diode without the $\mathrm{HF}$ pre-treatment, Fig. 2(a) shows a voltage hysteresis of $0.45 \mathrm{~V}$ when the bias is swept from $-4 \mathrm{~V}$ to $3 \mathrm{~V}$ and $3 \mathrm{~V}$ to $-4 \mathrm{~V}$. The diodes with the HF-treatment display a smaller hysteresis of $0.15 \mathrm{~V}$ under the same sweep conditions, indicating that the $\mathrm{HF}$ pre-treatment effectively reduces the interface states of the $\mathrm{Al}_{2} \mathrm{O}_{3} / \mathrm{GaN}$ MIS diode.

Two identical transistors from the sample with pre-treatment and the reference sample without pre-treatment were used for characterizations. The transfer characteristics for both of the devices are given in Fig. 3 in semi-log scale. Threshold voltage values were extracted using the drain current density of $1 \mathrm{~mA} / \mathrm{mm}$ as the criteria. Both devices show

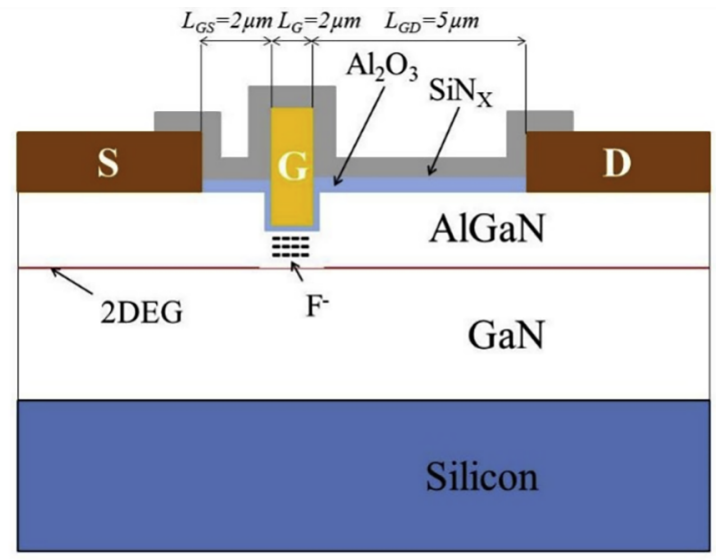

(a)

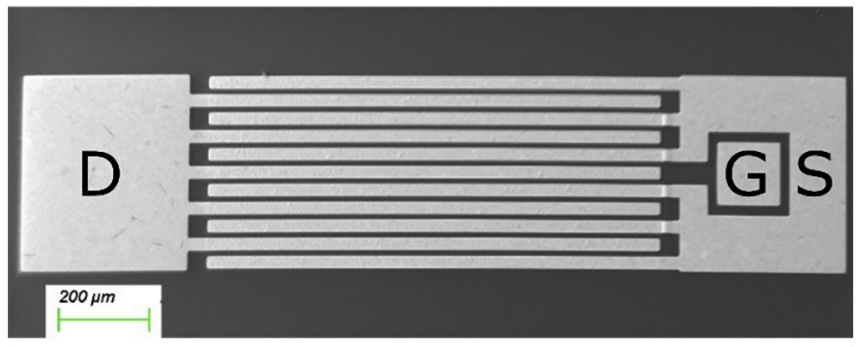

(b)

Fig. 1. a) Schematic cross-sectional view with gate length, gate to source distance, and gate to drain distance, and b) micrograph of the GaN MIS-HEMT. (single column figure).

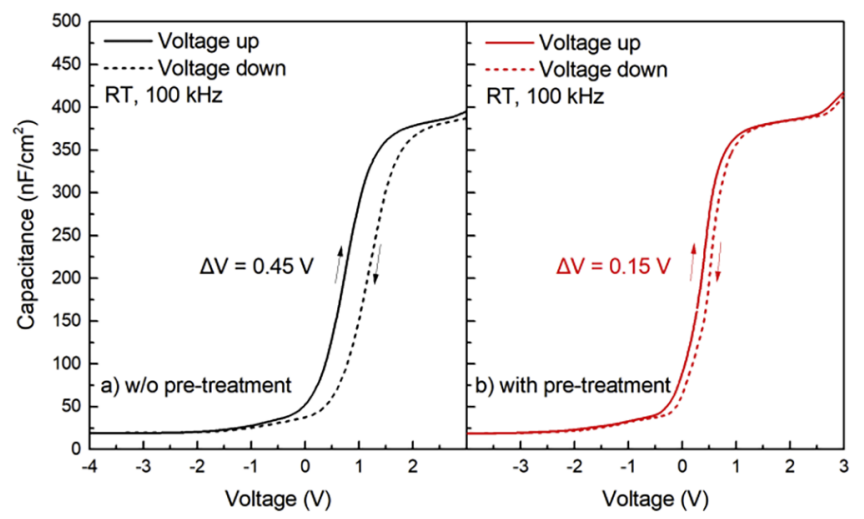

Fig. 2. $\mathrm{C}-\mathrm{V}$ characteristics of $\mathrm{Al}_{2} \mathrm{O}_{3} / \mathrm{GaN}$ MIS-diode a) without and b) with $\mathrm{HF}$ pre-treatment measured at room temperature at a frequency of $100 \mathrm{kHz}$. (single column figure).

normally-off characteristics. $\mathrm{V}_{\text {th }}=+2.05 \mathrm{~V}$ was obtained for the device with pre-treatment and $\mathrm{V}_{\mathrm{th}}=+2.16$ for the device without pre-treatment, indicating that the HF pre-treatment maintains the threshold voltage. When the device is pinched off, 2 orders of magnitude decrease is observed in the drain and gate current for the device with the pretreatment. The reduction in the gate current leads in an increase in the drain $\mathrm{ON} / \mathrm{OFF}$ drain-current ratio $\left(\mathrm{I}_{\mathrm{ON}} / \mathrm{I}_{\mathrm{OFF}}\right)$, from the order of $10^{4}-10^{6}$.

Gate leakage characteristics were measured by sweeping $V_{G}$ from $-8 \mathrm{~V}$ to $+6 \mathrm{~V}$ with the drain contact floating (Fig. 4). The reverse gate leakage current was extracted on the order of $10^{-10} \mathrm{~A} / \mathrm{mm}$ for the device with pre-treatment and $10^{-7} \mathrm{~A} / \mathrm{mm}$ for the device without pretreatment. The HF pre-treatment provided around 3-4 orders of magnitude improvement in gate leakage current. The device employing HF 


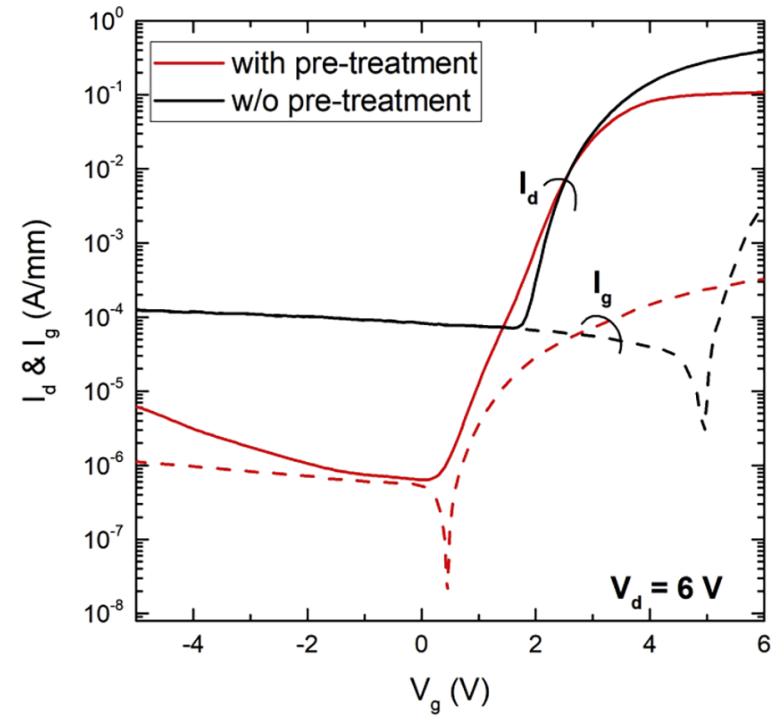

Fig. 3. Transfer characteristic of normally-off GaN MIS-HEMT with (red line) and without (black line) pre-treatment shown in semi-log scale. (single column figure).

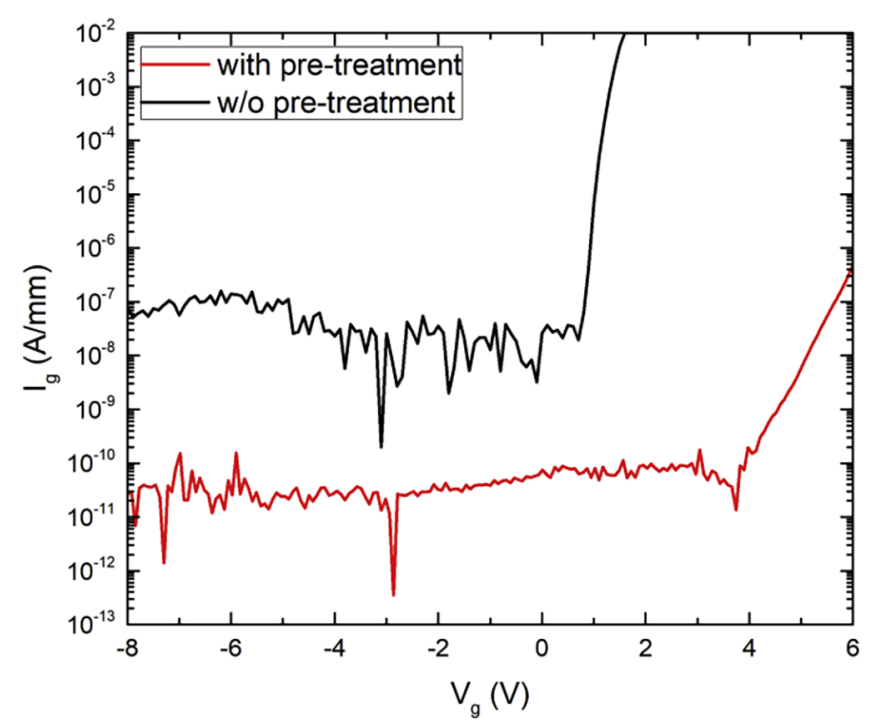

Fig. 4. Gate leakage current characteristics of the GaN MIS-HEMT with (red line) and without (black line) pretreatment. (single column figure).

pre-treatment also exhibits improved forward gate leakage current and a higher gate turn-on voltage. The low leakage for the device with pretreatment maintains up to $4 \mathrm{~V}$ after which it gradually increases to $5 \times 10^{-7} \mathrm{~A} / \mathrm{mm}$.

Pulsed hysteresis measurements were carried out to investigate the impact of the HF pre-treatment on the trapping behavior. The pulse width and pulse period are $500 \mu$ s and $50 \mathrm{~ms}$ respectively. The hysteresis curves are shown in Fig. 5. Transfer characteristics were obtained at a drain bias of $\mathrm{V}_{\mathrm{d}}=10 \mathrm{~V}$. For the $\mathrm{I}_{\mathrm{d}}-\mathrm{V}_{\mathrm{g}}$ hysteresis measurement the gate bias was swept from $-4 \mathrm{~V}$ to $6 \mathrm{~V}$ and from $6 \mathrm{~V}$ to $-4 \mathrm{~V}$. As shown in Fig. 4, the observed threshold voltage hysteresis $\Delta \mathrm{V}_{\text {th }}$ decreases from $0.58 \mathrm{~V}$ to $0.3 \mathrm{~V}$ for the device with pre-treatment, indicating that $\mathrm{HF}$ pre-treatment can effectively reduce interface trapping effects. A positive hysteresis is obtained for the device with pre-treatment and a negative hysteresis is obtained for the device without pre-treatment $\left(\Delta \mathrm{V}_{\text {th }}=\mathrm{V}_{\mathrm{g} \text {-down }}-\mathrm{V}_{\mathrm{g}-\mathrm{up}}\right)$. The output characteristics with step-up and step-down measurements were obtained for gate biases $V_{g}$ between $0 \mathrm{~V}$ and $5 \mathrm{~V}$. A positive and a negative $\mathrm{V}_{\text {th }}$ hysteresis were obtained for the sample with and without pre-treatment, respectively. The hysteresis in the device with pre-treatment is attributed to acceptor-like interface states, whereas the negative shift in the threshold voltage with the application of relatively negative gate bias in the device without pretreatment is thought to be additionally due to capture of electrons tunnelling from the gate by the localized states in the GaN buffer layer $[20,21]$. The opposite signs of voltage hysteresis for the devices without pre-treatment and with pre-treatment leads to an apparent higher threshold voltage for the device without pre-treatment. Both devices exhibit a maximum drain current of $I_{d}=180 \mathrm{~mA} / \mathrm{mm}$ at $V_{g}=5 \mathrm{~V}$. The MIS-HEMT with pre-treatment displays no obvious current slump, whereas current slump is observed for the device without the pretreatment.

The off-state breakdown/leakage characteristics of both devices are in shown Fig. 6. Gate electrodes were biased at $\mathrm{V}_{\mathrm{g}}=-6 \mathrm{~V}$. The breakdown voltages, defined as the drain bias at a drain leakage current of $1 \mathrm{~mA} / \mathrm{mm}$, are measured as $36 \mathrm{~V}$ and $32 \mathrm{~V}$ for the device with and without pre-treatment, respectively. It can be observed that the off-state gate leakage has been substantially suppressed by the pre-treatment.

To gain an insight on the structural properties of treated samples, $\mathrm{X}$ ray photoelectron spectroscopy (XPS) is employed. Fig. 7(a-b) shows the Ga3d, and N1s spectra of three different samples labeled as F1 (bare sample), F3 (recess and fluorine treated sample), and F4 (recess and fluorine treated sample with HF pre-treatment). X-ray photoelectron spectroscopy (XPS, Thermoscientific, Al K-Alpha radiation, hv = $1486.6 \mathrm{eV}$ ) measurement has been performed at survey mode by operating flood gun for surface charge neutralization with $30 \mathrm{eV}$ pass energy, $0.1 \mathrm{eV}$ step size, to determine surface elemental composition and the binding energy (BE) values. The calibration of the binding energy scale is performed by fixing the aliphatic C1s component at $284.8 \pm 0.1 \mathrm{eV}$ and shifting other peaks in the spectrum accordingly. As previously investigated, the dominant surface defects of $\mathrm{GaN}$ are $\mathrm{Ga}$ and $\mathrm{N}$ vacancies (or dangling bonds). Based on the calculation of free energy by classical nucleation theory, most of the oxygen-derived hydroxyl groups such as $\mathrm{OH}$ radicals and $\mathrm{H}_{2} \mathrm{O}$ or $\mathrm{O}_{2}$ will be chemisorbed near imperfections such as dangling bonds and vacancies. As clearly illustrated in Fig. 7(a), the Ga3d spectrum is deconvoluted into three Gaussian profiles [22]; a broad and weak response originated from N2s orbitals, a dominant peak assigned to Ga-N bond, and a high energy response from Ga-O bonds. As we go from F1 to F3, this oxide peak has been intensified, while it has been significantly suppressed in the F4 sample. The same behavior can be probed by exploring the N1s spectra. The N1s spectra is deconvoluted into five main peaks [23]; three of which are assigned into Auger Ga LMM peaks, the dominant one comes from Ga-N bond, and the one in the higher energy tail is attributed to $\mathrm{N}-\mathrm{O}$ bonds. As we can see, the same trend has been followed for $\mathrm{N}-\mathrm{O}$ related peak. From the above-mentioned results, it can be envisioned that the partial oxide layer on the starting sample has become dominant throughout the recess and etching process. However, the oxide layers have been removed from the surface via acid treatment process. Therefore, the final outcome (sample F4) has been efficiently passivated and the oxide layer has been removed.

Surface morphologies of the recess etched and fluorine treated regions before and after pre-treatments were determined by atomic force microscopy (AFM) in terms of root mean square (RMS) roughness over a $4.5 \times 4.5 \mu \mathrm{m}^{2}$ region, as shown in Fig. 8. The results of AFM measurement reveal that the surface morphologies improved with the HF wet etch cleaning pre-treatment. The RMS surface roughness displayed an improvement from $0.95 \mathrm{~nm}$ to $0.33 \mathrm{~nm}$ with the application of the pre-treatment. Additionally, AFM images of the $\mathrm{Al}_{2} \mathrm{O}_{3}$ dielectric surface both with and without HF pre-treatments are obtained (Fig. 9). A surface roughness of $0.47 \mathrm{~nm}$ is obtained for the $\mathrm{Al}_{2} \mathrm{O}_{3}$ surface without the pre-treatment and a surface roughness of $0.30 \mathrm{~nm}$ is obtained for the $\mathrm{Al}_{2} \mathrm{O}_{3}$ surface with the pre-treatment from a $2 \times 2 \mu \mathrm{m}^{2}$ region. The AFM measurements demonstrate that conformal coverage is obtained in both cases, with a slight improvement in smoothness observed for the sample with the pre-treatment. 

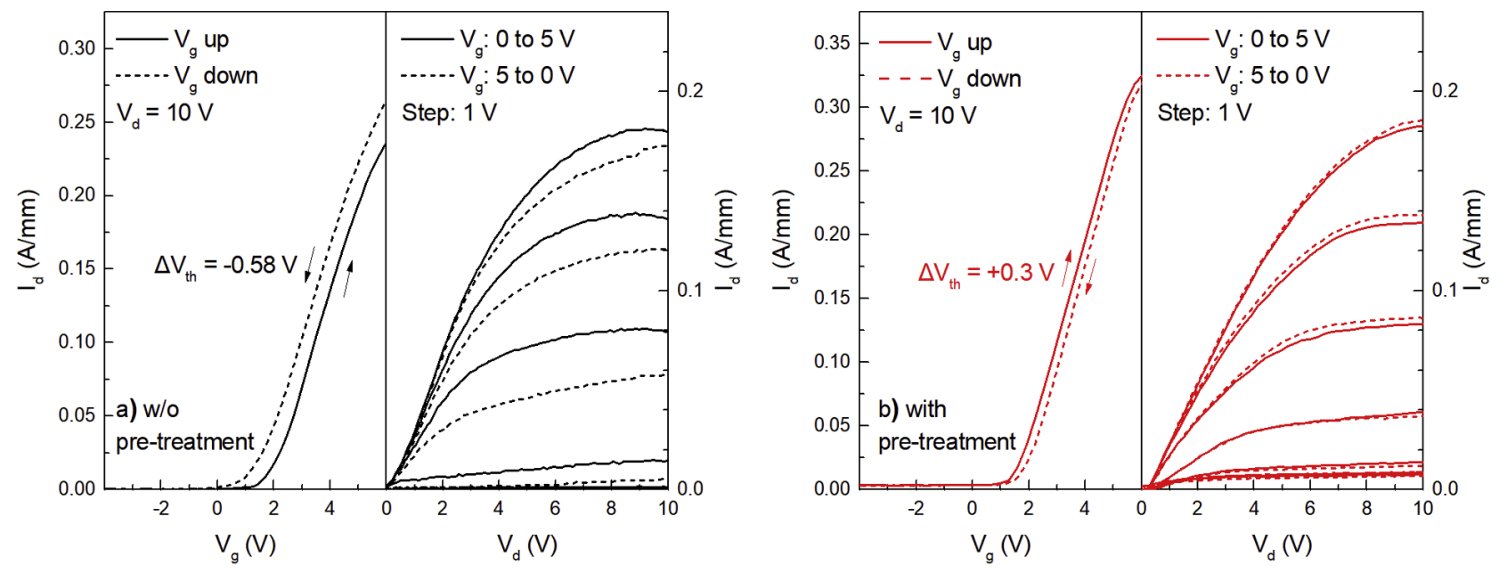

Fig. 5. Pulsed hysteresis measurements for the normally-off GaN MIS-HEMT a) without and b) with pretreatment. (double column figure).

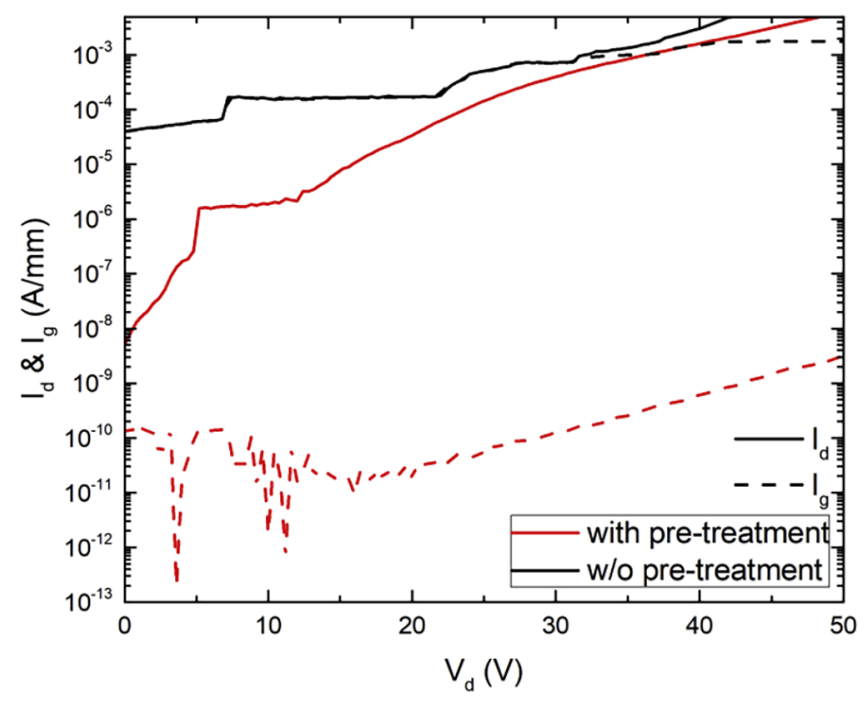

Fig. 6. Breakdown voltage characteristics of the device with (red line) and without (black line) pre-treatment. (single column figure).

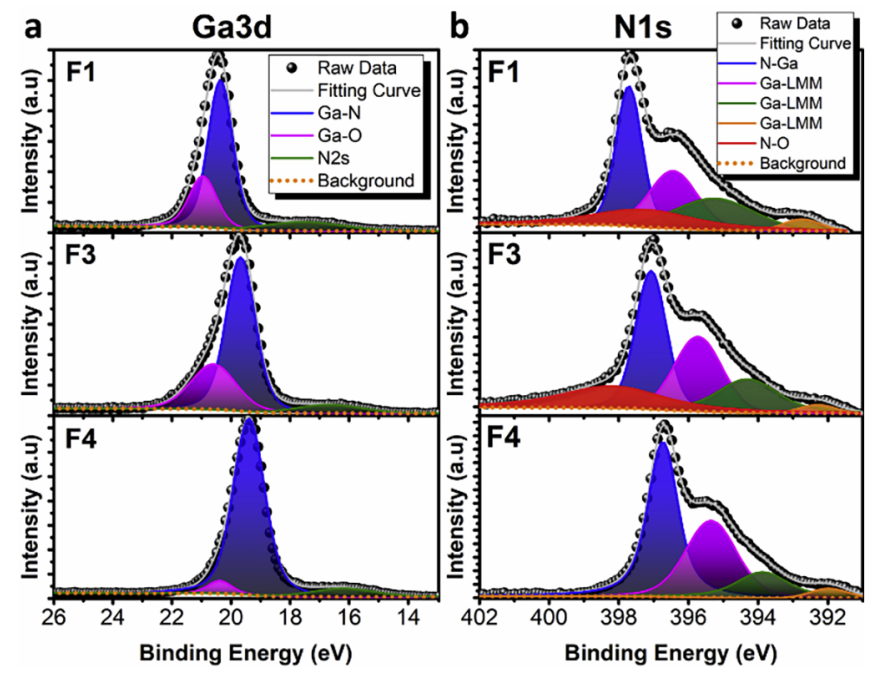

Fig. 7. High resolution XPS patterns of (a) Ga3d and (b) N1s the resulting F1, F3, and F4 samples, respectively. (single column figure).

It is known from previous reports that the dry etching methods used for recess etching method strongly affects the surface morphology of the etched regions, resulting in nitrogen vacancies and thereby more

\section{Sample without pre-treatment}

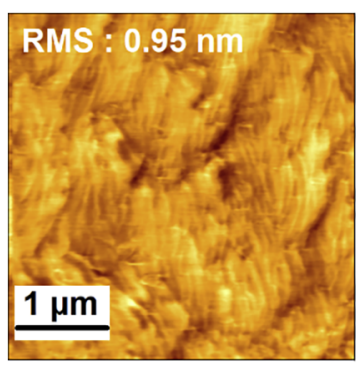

(a)

\section{Sample with pre-treatment}

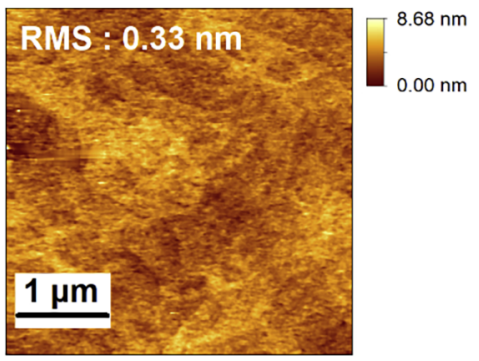

(b)
Fig. 8. Comparison of the AFM images for the AlGaN/GaN MIS-HEMT a) before and b) after HF pre-treatment. (single column figure).

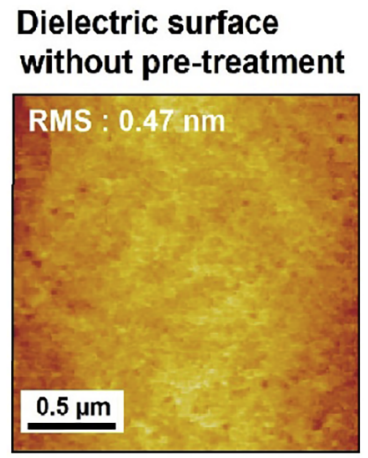

(a)

\section{Dielectric surface with pre-treatment}

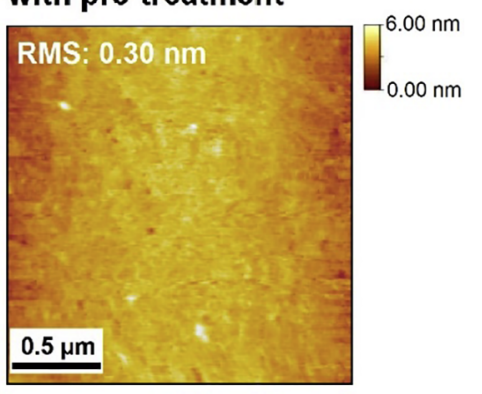

(b)
Fig. 9. Comparison of the $\mathrm{AFM}$ images for the $\mathrm{Al}_{2} \mathrm{O}_{3}$ dielectric surface a) without and b) with HF pre-treatment. (single column figure).

surface oxidation occurs [24,25]. Ref. [26] states that HF-based and other types of pre-treatments prior to $\mathrm{ALD} \mathrm{Al}_{2} \mathrm{O}_{3}$ are advantageous for providing an optimal surface. The X-ray photoelectron spectroscopy (XPS) and atomic force microscopy (AFM) analyses carried out confirm that the HF pre-treatment reduces the surface oxides and roughness while maintaining normally-off operation.

\section{Conclusion}

An AlGaN/GaN normally-off MIS-HEMT with utilizing a hydrofluoric acid pre-gate surface treatment is reported to improve the gate leakage current. A gate leakage current as low as on the order of 
$10^{-11} \mathrm{~A} / \mathrm{mm}$ is obtained. The comparative results of our study between the reference sample without pre-treatment and with pre-treatment show that HF pre-treatment results in a 3-4 order of magnitude improvement in the gate leakage current. Normally-off operation is maintained no degradation is introduced to the on-state performance.

\section{Declaration of Competing Interest}

None.

\section{Acknowledgements}

This work is supported by TUBITAK under Project PELIGAN No. 5160062. One of the authors (E.O.) also acknowledges partial support from the Turkish Academy of Sciences.

\section{Appendix A. Supplementary data}

Supplementary data to this article can be found online at https:// doi.org/10.1016/j.sse.2019.05.008.

\section{References}

[1] Saito W, Takada Y, Kuraguchi M, Tsuda K, Omura I. Recessed-gate structure approach toward normally off high-voltage AlGaN/GaN HEMT for power electronics applications. IEEE Trans Electron Devices 2006;53(2):356-62. https://doi.org/10. 1109/TED.2005.862708.

[2] Uemoto Y, Hikita M, Ueno H, Matsuo H, Ishida H, Yanagihara M, et al. Gate injection transistor (GIT) — A normally-off AlGaN/GaN power transistor using conductivity modulation. IEEE Trans Electron Devices 2007;54(12):3393-9. https:// doi.org/10.1109/TED.2007.908601.

[3] Cai Y, Zhou Y, Chen KJ, Lau KM. High-performance enhancement-mode AlGaN/ GaN HEMTs using fluoride-based plasma treatment. IEEE Electron Device Lett 2005;26(7):435-7. https://doi.org/10.1109/LED.2005.851122.

[4] Lin S, Wang M, Sang F, Tao M, Wen CP, Xie B, et al. HEMT structure allowing selfterminated, plasma-free etching for high uniformity, high-mobility enhancementmode devices. IEEE Electron Device Lett Apr. 2016;37(4):377-80. https://doi.org/ 10.1109/LED.2016.2533422.

[5] Shi Y, Huang S, Bao Q, Wang X, Wei K, Jiang H, et al. Normally off GaN-on-Si MISHEMTs fabricated with LPCVD-SiNx passivation and high-temperature gate recess. IEEE Trans Electron Devices Feb. 2016;63(2):614-9. https://doi.org/10.1109/TED. 2015.2510630 .

[6] Zhou Q, Chen B, Jin Y, Huang S, Wei K, Liu X, et al. High-performance enhancement-mode Al2O3/AlGaN/GaN- on-Si MISFETs with $626 \mathrm{MW} / \mathrm{cm} 2$ figure of merit. IEEE Trans. Electron Devices Mar. 2015;62(3):776-81. https://doi.org/10.1109/ TED.2014.2385062.

[7] Yang S, Liu S, Liu C, Tang Z, Lu Y, Chen KJ. Thermally induced threshold voltage instability of III-nitride MIS-HEMTs and MOSC-HEMTs: underlying mechanisms and optimization schemes. IEDM Tech Dig Dec 2014:17.2.1-4. https://doi.org/10. 1109/IEDM.2014.7047069.

[8] Sun X, Zhang Y, Chang-Liao K, Palacios T, Ma T. Impacts of fluorine-treatment on Emode AlGaN/GaN MOS-HEMTs. In: Electron Devices Meeting (IEDM), 2014 IEEE International, 2014, IEEE. p. 17.3. 1-17.3. 4.

[9] Wang R, Saunier P, Tang Y, Fang T, Gao X, Guo S, et al. Enhancement-mode InAlN/ AlN/GaN HEMTs with 10-12 A/mm leakage current and $10^{12}$ on/off current ratio. IEEE Electron Device Lett. Mar. 2011;32(3):309-11. https://doi.org/10.1109/LED. 2010.2095494.

[10] Lee N-H, Lee M, Choi W, Kim D, Jeon N, Choi S, et al. Effects of various surface treatments on gate leakage, subthreshold slope, and current collapse in AlGaN/GaN high-electron-mobility transistors. Jpn J Appl Phys Mar. 2014;53(4S):1-5.

[11] Yang S, Tang Z, Wong K-Y, Lin Y-S, Liu C, Lu Y, et al. High-quality interface in $\mathrm{Al} 2 \mathrm{O} 3 / \mathrm{GaN} / \mathrm{AlGaN} / \mathrm{GaN}$ MIS structures with in situ pre-gate plasma nitridation. IEEE Electron Device Lett. Dec. 2013;34(12):1497-9. https://doi.org/10.1109/ LED. 2013.2286090.

[12] Deguchi T, Kikuchi T, Arai M, Yamasaki K, Egawa T. High on/off current ratio pInGaN/AlGaN/GaN HEMTs. IEEE Electron Device Lett Sep. 2012;33(9):1249-51. https://doi.org/10.1109/LED.2012.2204854.

[13] Lin Y, Lain Y, Hsu SSH. AlGaN/GaN HEMTs with low leakage current and high on/ off current ratio. IEEE Electron Device Lett Feb. 2010;31(2):102-4. https://doi.org/ 10.1109/LED.2009.2036576.

[14] Lu1 X, Jiang H, Liu C, Zou X, Lau KM. Off-state leakage current reduction in AlGaN/ GaN high electron mobility transistors by combining surface treatment and postgate annealing. Semicond Sci Technol 2016;31:1-7. https://doi.org/10.1088/0268$1242 / 31 / 5 / 055019$.

[15] Freedsman JJ, Egawa T, Yamaoka Y, Yano Y, Ubukata A, Tabuchi T, Matsumoto K. Normally-off $\mathrm{Al}_{2} \mathrm{O}_{3} / \mathrm{AlGaN} / \mathrm{GaN}$ MOS-HEMT on $8 \mathrm{in}$. Si with low leakage current and high breakdown voltage (825 V). Appl Phys Exp 2014;7(4):041003. https:// doi.org/10.7567/APEX.7.041003.

[16] Wu C-H, Han P-C, Luc QH, Hsu C-Y, Hsieh T-E, Wang H-C, et al. Normally-off GaN
MIS-HEMT with F- doped gate insulator using standard ion implantation. IEEE $J$ Electron Devices Soc 2018:1. https://doi.org/10.1109/JEDS. 2018.2859769.

[17] Kurt G, et al. Investigation of a Hybrid Approach for Normally-Off GaN HEMTs Using Fluorine Treatment and Recess Etch Techniques. IEEE J Electron Devices Soc 2019;7:351-7. https://doi.org/10.1109/JEDS.2019.2899387.

[18] Tseng M-C, Hung M-H, Wuu D-S, Horng R-H. Study of interface state trap density on characteristics of MOS-HEMT. In: Proc. SPIE 9363, Gallium Nitride Materials and Devices X, Mar. 2013. DOI: $10.1117 / 12.2076678$.

[19] Jia Y, Wallace JS, Echeverria E, Gardella Jr. JA, Singisetti U. Interface characterization of atomic layer deposited $\mathrm{Al}_{2} \mathrm{O}_{3}$ on m-plane GaN. Phys Status Solidi B Feb. 2017;254(8):1600681. https://doi.org/10.1002/pssb.201600681.

[20] Zhang Z, Li W, Fu K, Yu G, Zhang X, Zhao Y, et al. AlGaN/GaN MIS-HEMTs of verylow $\mathrm{V}_{\text {th }}$ hysteresis and current collapse with in-situ pre-deposition plasma nitridation and LPCVD-Si3N4 gate insulator. IEEE Electron Device Lett 2017;38:236-9. https://doi.org/10.1109/LED.2016.2636136.

[21] Polyakov A, Smirnov N, Govorkov A, Markov A, Dabiran A, Wowchak A, et al. Deep traps responsible for hysteresis in capacitance-voltage characteristics of AlGaN/ GaN heterostructure transistors. Appl Phys Lett 2007;91:232116https://doi.org/10. $1063 / 1.2823607$.

[22] Huang R, Liu T, Zhao Y, Zhu Y, Huang Z, Li F, et al. Angular dependent XPS study of surface band bending on Ga-polar n-GaN. Appl Surf Sci 2018;440:637-42. https:// doi.org/10.1016/j.apsusc.2018.01.196.

[23] Stoklas R, Gregušová D, Blaho M, Fröhlich K, Novák J, Matys M, et al. Influence of oxygen-plasma treatment on AlGaN/GaN metal-oxide-semiconductor heterostructure field-effect transistors with $\mathrm{HfO} 2$ by atomic layer deposition: leakage current and density of states reduction. Semicond Sci Technol 2017;32:045018https://doi.org/10.1088/1361-6641/aa5fcb.

[24] Sang F, Wang MJ, Tao M, Liu SF, Yu M, Xie B, et al. Time-dependent threshold voltage drift induced by interface traps in normally-off GaN MOSFET with different gate recess technique. Appl Phys Express Jul. 2016;9(9):091001https://doi.org/10. 7567/APEX.9.091001.

[25] Yin R, Li Y, Sun Y, Wen CP, Hao Y, Wang M. Correlation between border traps and exposed surface properties in gate recessed normally-off $\mathrm{Al}_{2} \mathrm{O}_{3} / \mathrm{GaN}$ MOSFET. Appl Phys Lett May. 2018:112(23):233505https://doi.org/10.1063/1.5037646.

[26] Nepal N, Garces1 NY, Meyer DJ, Hite JK, Mastro MA, Eddy Jr CR. Assessment of GaN surface pretreatment for atomic layer deposited high-k dielectrics. Appl Phys Express 2011;4(5). https://doi.org/10.1143/APEX.4.055802. 055802.

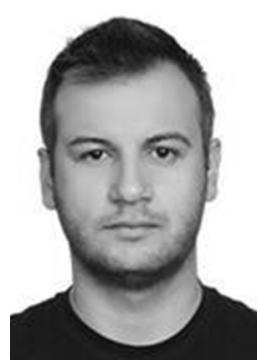

Gokhan Kurt was born in Ankara, Turkey in 1983. He received the B.S. degree and the master's degree from the Department of Physics Engineering, Ankara University, in Ankara, Turkey in 2006. He is currently a Ph.D. Candidate in the same department of Ankara University. He has also been working as a senior research engineer at Nanotechnology Research, Center of Bilkent University since 2009. His current research interests include GaNbased power devices, RF and microwave nanotransistors, $\mathrm{RF}$ power and high-frequency applications, GaN-based HEMTs, microfabrication of micro integrated circuits and transistors.

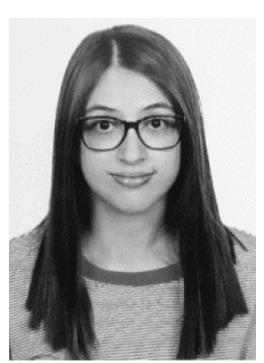

Melisa Ekin Gulseren received the B.S. degree in electrical and electronics engineering from Bilkent University, Ankara, Turkey in 2016 and is currently pursuing the M.S. degree at the same institution. Since 2016, she is a Research Assistant with the Bilkent University Nanotechnology Research Center (NANOTAM), Ankara, Turkey. Her research interests include wide bandgap devices, III-V nitride electronics, and fabrication of micro- or nanostructures.

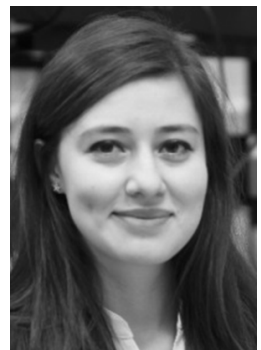

Turkan Gamze Ulusoy Ghobadi received her BS degree in Chemical Engineering from Ankara University, Turkey in 2012. She joined the National Nanotechnology Research Center (UNAM), Institute of Materials Science and Nanotechnology, Bilkent University, Turkey and obtained MS degree in 2015. Currently, she is pursuing her $\mathrm{PhD}$ degree in the same department under the guidance of Asst. Prof Ferdi Karadas from the Chemistry Dept. and co-supervised by Prof. Ekmel Ozbay from Physics Department and EEE Department. She became a research assistant in the Dept. of Energy Engineering at Ankara University in 2017. Her current research interests focus on the development of (photo)electrochemical materials for energy storage and conversion systems. 


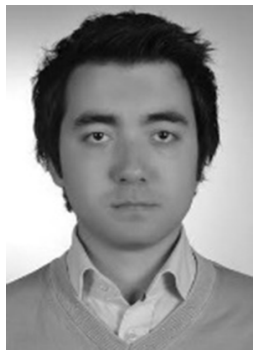

Sertac Ural received the B.S. degree from Department of Physics Engineering, Ankara University, Ankara, Turkey, in 2014. Since 2015, he has been a Process Engineer at Bilkent University Nanotechnology Research Center, Ankara, Turkey. He is mainly working on MOCVD growth, characterization and physics of GaN-based technologies.

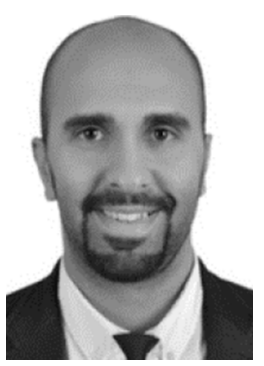

Ömer Ahmet Kayal received the B.S. from the Department of Physics Engineering, Hacettepe University, Ankara, Turkey, in 2015. In 2015, he joined the Nanotechnology Research Center as a process engineer in Bilkent University, Ankara, Turkey. He mainly works on MOCVD growth, material characterization and device physics of GaN-based HEMTs.

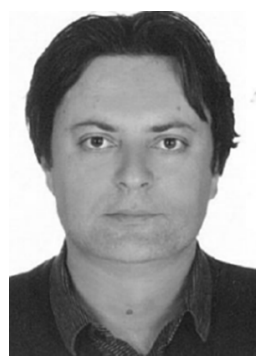

Mustafa Ozturk was born in Manisa province in Turkey in 1982. He received the B.S from the Department of Physics Engineering at Hacettepe University, and M.S from Department of Advanced Technologies in Gazi University, Ankara in 2006 and 2011 respectively. He worked as a Project engineer in Bilkent University Nanotechnology Research Center from 2006 to 2011, and then he joined to MOCVD tool maker company (Aixtron SE) in Aachen Germany and worked as a field process engineer till 2016. In April 2016, he started to work as an Epitaxy Group Leader in Bilkent Nanotam until the present day.

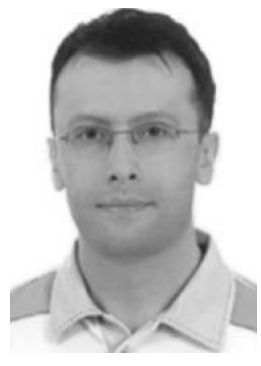

Bayram Butun received his B.S., M.S., and Ph.D. (2010) degrees in Electrical and Electronics Engineering from Bilkent University, Ankara, Turkey. He has been working as a researcher in Nanotechnology Research Center, Bilkent University. He worked on design, fabrication, and characterization of $\mathrm{Si}, \mathrm{GaAs}$, InP and III-N based high-performance photodiodes, III-N based light emitting diodes hybridized with organic polymers, GaAs based laser diodes, MWIR Quantum Cascade Lasers, terahertz time-domain spectroscopy and photonic crystals. Dr. Butun's current research interest is focused on nanoscale plasmonics, TCAD simulation of GaN-based HEMTs and process development of high power e-mode HEMT structures.

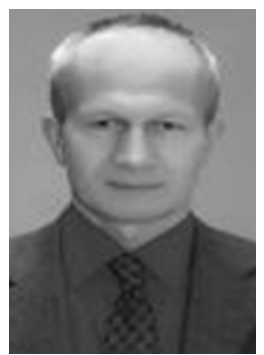

Mehmet Kabak graduated from Department of Engineering Physics of Ankara University, Turkey in 1987 and received his academic degrees from the same department. He has been a full professor since 2009. Prof. Kabaks research areas include molecular mechanics and molecular orbital methods, ab-initio and semi-empirical quantum mechanical calculations single and powder crystal x-ray diffraction, magnetic, electric and specific heat properties of rare earth compounds, numerical methods, and its applications.

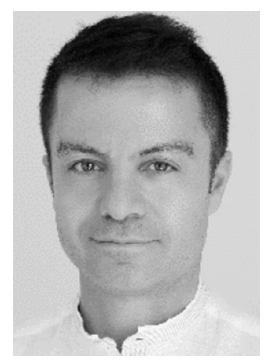

Ekmel Ozbay Prof. Dr. Ekmel Ozbay received M.S. and Ph. D. degrees from Stanford University in electrical engineering, in 1989 and 1992 . He worked as a postdoctoral research associate in Stanford University and he worked as a scientist in Iowa State University. He joined Bilkent University (Ankara, Turkey) in 1995, where he is currently a full professor in Physics Department and EEE Department. In 2003, he founded Bilkent University Nanotechnology Research Center (NANOTAM) where he leads a research group working on nanophotonics, nanometamaterials, nanoelectronics, GaN AlGaN MOCVD growth, and GaN based devices. He is the 1997 recipient of the Adolph Lomb Medal of OSA and 2005 European Union Descartes Science award. He worked as an editor for Nature Scientific Reports, Optics Letters, PNFA, and IEEE JQE journals. He has published $440+$ articles in SCI journals. His papers have received $14500+$ SCI citations with an SCI h-index of 57. He has given $155+$ invited talks in international conferences. He recently became the CEO of a spin-off company: AB-MicroNano Inc. 